\title{
MICROPROPAGAÇÃO DO PORTA-ENXERTO DE MACIEIRA 'Seleção 69' TOLERANTE À PODRIDÃO DO COLO (Phytophthora cactorum)
}

\author{
MICROPROPAGATION OF 'Seleção 69' APPLE ROOTSTOCK TOLERANT \\ THE ROTTING (Phytophthora cactorum)
}

\section{Claudete Santa-Catarina ${ }^{1}$ Scheila da Conceição Maciel $^{2}$ Frederico Denardi ${ }^{3}$ Enio Luiz Pedrotti ${ }^{4}$}

RESUMO

A utilização de porta-enxertos anões, tolerantes a problemas fitossanitários da cultura da macieira, como a podridão do colo (Phytophthora cactorum), pode aumentar o rendimento e reduzir os custos de produção. Com o presente trabalho, objetivou-se estabelecer um protocolo de micropropagação do porta-enxerto 'Seleção 69', tolerante à podridão do colo. Ápices meristemáticos foram cultivados in vitro em meio de cultura MS, suplementado com 4,4 $\mu M$ de 6-Benzilaminopurina (BAP), 2,5 $\mu M$ de Ácido indolbutírico (AIB), 0,3 $\mu M$ de Ácido giberélico $\left(\mathrm{GA}_{3}\right)$, $3 \%$ de sacarose e 0,6\% de ágar. Foram testados o efeito da concentração de BAP $(2,2$ e 4,4 $4 M)$ e o efeito dos meios de cultura (MS, Cheng e Quoirin \& Lepoivre) na multiplicação das brotações. No alongamento das brotações, foram testados os efeitos do $\mathrm{GA}_{3}(0 ; 0,5 ; 1,0$ e 1,5 $\mathrm{\mu M})$ e AIB $(0 ; 0,5$ e 1,0 $\mu \mathrm{M})$. Para a fase de enraizamento ex vitro e aclimatização, foram testadas diferentes concentrações de AIB $\left(0 ; 1\right.$ e $\left.2 \mathrm{~g} \mathrm{~L}^{-1}\right)$. A taxa de desenvolvimento dos ápices meristemáticos cultivados in vitro foi de $30 \%$. Para estimular a brotação, a melhor concentração de BAP foi 2,2 $\mu \mathrm{M}$, a qual proporcionou 2,6 brotações por explante. $O$ meio MS proporcionou o maior número de brotações por explante (2,5), porém não diferiu estatisticamente do meio Cheng (2,0 brotações por explante). Para a fase de alongamento, o meio MS suplementado com 2,2 $\mu M$ de BAP e 1,0 $\mu M$ de AIB, proporcionou a maior altura das brotações $(23 \mathrm{~mm})$. Na fase de enraizamento ex vitro e aclimatização, as concentrações de 0,1 e $2 \mathrm{~g} \mathrm{~L}^{-1}$ de AIB possibilitaram em média, $77,3 \%$ de enraizamento das microestacas.

Palavras-chave: ápices meristemáticos, cultura in vitro, enraizamento ex vitro, aclimatização.

\section{SUMMARY}

The use of tolerant apple rootstocks to phytossanitary problems as the rotting (Phytophthora cactorum) is able to increase the production with cost reduction. The objective of the present study is to establish in vitro micropropagation protocol of the '69 Selection' rootstocks tolerant to the rotting. Meristems was cultivated in vitro on MS medium supplemented with 4.4 $\mu \mathrm{M}$ of 6-Benzilaminopurine (BAP), $2.5 \mu M$ of Indol Butiric Acid (IBA), 0.3 $\mu M$ of Giberilic Acid $\left(G A_{3}\right)$, $3 \%$ of sucrose and $0.6 \%$ of agar. The effect of BAP concentration $(2.2$ and $4.4 \mu M)$ and the effect of culture media (MS, Cheng and Quoirin \& Lepoivre) were tested in the shoot multiplication. In the shoot elongation phase, the effects of $\mathrm{GA}_{3}(0 ; 0.5 ; 1.0$ and $1.5 \mu M)$ and IBA $(0 ; 0.5$ and $1.0 \mu M)$ were tested. During the rooting ex vitro and acclimatization phase, different IBA concentrations $\left(0 ; 1\right.$ and $\left.2 \mathrm{~g} \mathrm{~L}^{-1}\right)$ were tested. The rate of acme meristems development was $30 \%$ of the meristems cultivated in vitro. For the shoot number, the best BAP concentration was $2.2 \mu M$ that provided 2.6 shoots/explant. The MS medium provided the largest shoot number for explant (2.5), however it was not differing of Cheng medium (2.0 shoots/explant). For the shoot elongation phase, the MS medium supplemented 1.0 $\mu \mathrm{M}$ of $I B A$ provided the largest height of shoots $(23 \mathrm{~mm})$. In the ex vitro rooting and acclimatization phase, the $0,1.0$ and $2.0 \mathrm{~g} \mathrm{~L}^{-1}$ of IBA concentrations, were able to achieve on average of $77,3 \%$ of microcuttings rooting.

Key words: meristem culture, in vitro culture, ex vitro rooting, acclimatization.

\section{INTRODUÇÃO}

O Estado de Santa Catarina destaca-se como o maior produtor de maçãs, totalizando em torno de $60 \%$ da produção nacional (ASSOCIAÇÃO BRASILEIRA DE PRODUTORES DE MAÇÃ,

\footnotetext{
${ }^{1}$ Engenheiro Agrônomo, Mestranda em Biologia Vegetal, CCB - Universidade Federal de Santa Catarina (UFSC).

${ }^{2}$ Engenheiro Agrônomo, CCA, UFSC.

${ }^{3}$ Engenheiro Agrônomo, Mestre, Estação Experimental Epagri de Caçador, SC.

${ }^{4}$ Engenheiro Agrônomo, Professor Adjunto, Departamento de Fitotecnia, CCA, UFSC, 88010-970, Florianópolis, SC. Email:pedrotti@cca.ufsc.br. Autor para correspondência.
} 
1999). A produção atual, em torno de 800 mil toneladas, já está suprindo a demanda nacional, com 50 toneladas do produto exportadas na safra de 1999 (CENTELLAS et al., 1999; ASSOCIAÇÃO BRASILEIRA DE PRODUTORES DE MAÇÃ, 1999). Entretanto, persistem ainda problemas de qualidade e os custos de produção ainda são elevados. Dentre os fatores responsáveis pelo custo de produção, o controle fitossanitário representa mais de $30 \%$ do total, visto que os produtores vêm empregando porta-enxertos suscetíveis aos principais organismos fitopatogênicos do solo, como a podridão do colo (Phytophthora cactorum), podridão-branca (Rosellinia necatrix) e pulgão lanígero (Eriosoma lanigerum).

Com o objetivo de selecionar novos portaenxertos resistentes a estes organismos, a Empresa de Pesquisa Agropecuária e Extensão Rural de Santa Catarina S.A. (Epagri) tem desenvolvido trabalhos de introdução de novos genótipos. Dentre os novos porta-enxertos introduzidos, alguns são promissores por apresentarem resistência simultânea à podridão do colo e ao pulgão lanígero (DENARDI \& BERTON, 1995), dentre eles a 'Seleção 69'. Por esta razão, poderão substituir os atuais portaenxertos das séries ' $M$ ' e 'MM', todos suscetíveis a um ou mais desses organismos.

A possível substituição dos porta-enxertos por novas opções, requer, entretanto, a disponibilidade de grande quantidade de material propagativo. A micropropagação via cultura de meristemas é uma técnica viável para a propagação massal, pois apresenta elevadas taxas de multiplicação comparada aos métodos convencionais de propagação. Para a macieira, RIBAS \& ZANETTE (1992) e YUI et al. (1993) desenvolveram protocolos de micropropagação a partir da cultura de meristemas, e NUNES $\boldsymbol{e t}$ al. (1999) e DIAZ-PÉREZ et al. (1995) estabeleceram protocolos para o enraizamento e aclimatização de plantas de macieira micropropagadas. Com isto, abrem-se perspectivas para o uso desta técnica em programas de produção comercial de clones geneticamente superiores.

O objetivo deste trabalho foi estabelecer um protocolo de micropropagação do porta-enxerto de macieira 'Seleção 69' a partir de ápices meristemáticos.

\section{MATERIAL E MÉTODOS}

Obtenção, assepsia e cultivo dos ápices meristemáticos

Os ápices meristemáticos de 2 a $4 \mathrm{~mm}$, contendo 2 a 3 primórdios foliares adjacentes, foram retirados de gemas apicais de plantas matrizes do porta-enxerto 'Seleção 69', mantidas em casa de vegetação. A assepsia foi realizada através da imersão das gemas apicais em etanol $70 \%$ (v:v) por 1 minuto e hipoclorito de sódio $1 \%$ por 20 minutos, seguido de 3 lavagens em água destilada e autoclavada em câmara de fluxo laminar. As gemas apicais foram mantidas em solução de ácido ascórbico a $1,5 \%$ durante 15 minutos, e posteriormente, foram obtidos os ápices meristemáticos.

Os ápices meristemáticos foram inoculados em meio de cultura MS (MURASHIGE \& SKOOG, 1962), suplementado com 4,4 $\mu \mathrm{M}$ de BAP (6-benzilaminopurina), 2,5 $\mu \mathrm{M}$ de AIB (ácido indolbutírico), 0,3 $\mu \mathrm{M}$ de $\mathrm{GA}_{3}$ (ácido giberélico), 3\% de sacarose e $0,6 \%$ de ágar. As culturas foram transferidas para a sala de crescimento e mantidas na temperatura de $25 \pm 1^{\circ} \mathrm{C}$, na ausência de luz durante 5 dias. Posteriormente, foram colocados em presença de luz com intensidade de $40 \mu \mathrm{mol} \mathrm{m} \mathrm{m}^{-2} \mathrm{~s}^{-1}$ e fotoperíodo de 16 horas.

\section{Indução de brotações}

Para quantificar o efeito do BAP sobre a taxa de multiplicação das brotações, segmentos nodais de 8 a $10 \mathrm{~mm}$ de altura foram inoculados em meio de cultura MS, suplementado com 3\% de sacarose e $0,6 \%$ de ágar, na presença de 2,2 ou $4,4 \mu \mathrm{M}$ de BAP. As culturas foram mantidas em sala de crescimento com temperatura de $25 \pm 1^{\circ} \mathrm{C}$, intensidade luminosa de $40 \mu \mathrm{mol} \mathrm{m} \mathrm{m}^{-2} \mathrm{~s}^{-1}$ e fotoperíodo de 16 horas de luz. Após 40 dias de cultivo foram avaliados o número de brotações maiores de que $5 \mathrm{~mm}$ de altura. $\mathrm{O}$ delineamento experimental utilizado foi o completamente casualizado, composto por cinco repetições contendo cinco explantes cada.

\section{Multiplicação das brotações em diferentes com- posições salinas}

Para quantificar o efeito de diferentes composições salinas dos meios de cultura sobre a taxa de multiplicação das brotações, segmentos nodais de 8 a $10 \mathrm{~mm}$ de altura foram inoculados nos seguintes meios de cultura: 1) MS; 2) Cheng (CHENG, 1978) e 3) QL (QUOIRIN \& LEPOIVRE, 1977). A estes meios de cultura, foram adicionados $2,2 \mu \mathrm{M}$ de BAP, $3 \%$ de sacarose e $0,6 \%$ de ágar. As culturas foram mantidas em sala de crescimento com as mesmas características do experimento anterior. Após 50 dias de cultivo, foram avaliados o número de brotações maiores do que $5 \mathrm{~mm}$ e a altura das brotações. $\mathrm{O}$ delineamento experimental utilizado foi o completamente casualizado, composto por cinco repetições contendo cinco segmentos nodais cada. 


\section{Alongamento das brotações}

Para testar o efeito de fitorreguladores de crescimento sobre o alongamento das brotações, segmentos nodais de 8 a $10 \mathrm{~mm}$, foram inoculados em meio de cultura MS, suplementado com $3 \%$ de sacarose, $0,6 \%$ de ágar, na presença de BAP e/ou variando a concentração de $\mathrm{AIB}$ e $\mathrm{GA}_{3}$. Os tratamentos foram: 1) $2,2 \mu \mathrm{M}$ de BAP; 2) $2,2 \mu \mathrm{M}$ de BAP $+0,5 \mu \mathrm{M}$ de $\mathrm{GA}_{3}$; 3) $2,2 \mu \mathrm{M}$ de $\mathrm{BAP}+1,0 \mu \mathrm{M}$ de $\mathrm{GA}_{3}$; 4) $2,2 \mu \mathrm{M}$ de $\mathrm{BAP}+1,5 \mu \mathrm{M}$ de $\mathrm{GA}_{3}$; 5) $2,2 \mu \mathrm{M}$ de $\mathrm{BAP}+0,5 \mu \mathrm{M}$ de AIB; 6) $2,2 \mu \mathrm{M}$ de BAP + $1,0 \mu \mathrm{M}$ de AIB; 7) $2,2 \mu \mathrm{M}$ de $\mathrm{BAP}+1,0 \mu \mathrm{M}$ de AIB $+1,5 \mu \mathrm{M}$ de $\mathrm{GA}_{3}$. As culturas foram mantidas em sala de crescimento com as mesmas características supracitadas. Após 50 dias de cultivo, foram avaliados o número e a altura das brotações maiores do que $5 \mathrm{~mm}$ e o número de gemas por brotação. $\mathrm{O}$ delineamento experimental utilizado foi o completamente casualizado, composto por cinco repetições contendo cinco segmentos nodais cada.

\section{Enraizamento ex vitro e aclimatização}

Para quantificar o efeito de concentrações de AIB sobre o enraizamento $\boldsymbol{e x}$ vitro, foram utilizadas microestacas de 10 a $15 \mathrm{~mm}$ de altura, oriundas do cultivo in vitro. As bases das microestacas foram imersas nas soluções de AIB de 0,1 e $2 \mathrm{~g} . \mathrm{L}^{-1}$ por 10 segundos e transferidas para bandejas alveoladas contendo substrato composto de solo argiloso (terra roxa estruturada) e casca de arroz carbonizada, na proporção de 1:1 (v:v). As bandejas foram colocadas em caixas plásticas e cobertas com placas de vidro transparente. Após, foram transferidas para sala de aclimatização, com intensidade luminosa de $40 \mu \mathrm{mol}$ $\mathrm{m}^{-2} \mathrm{~s}^{-1}$, fotoperíodo de 16 horas de luz e umidade relativa de $100 \%$, conforme metodologia utilizada por PEDROTTI (1993). A percentagem de enraizamento, a altura da parte aérea, o número e comprimento das raízes e o número de folhas foram avaliados após 30 dias de cultivo. O delineamento experimental utilizado foi o completamente casualizado, composto por cinco repetições contendo cinco microestacas cada.

\section{Análise dos dados}

Os resultados dos experimentos foram submetidos à análise da variância e ao teste de separação de médias de Duncan ao nível de $5 \%$ de probabilidade de erro.

\section{RESULTADOS E DISCUSSÃO}

\section{Cultivo dos ápices meristemáticos}

$\mathrm{O}$ meio MS, suplementado com $4,4 \mu \mathrm{M}$ de BAP, $2,5 \mu \mathrm{M}$ de AIB e $0,3 \mu \mathrm{M}$ de $\mathrm{GA}_{3}$ foi eficiente para o estabelecimento e crescimento in vitro dos ápices meristemáticos. Neste meio, 30\% dos ápices meristemáticos se desenvolveram, dando origem a eixos caulinares, $30 \%$ oxidaram e necrosaram, e $40 \%$ deles apresentaram contaminações por bactérias. Resultados que corroboram os obtidos por RIBAS \& ZANETTE (1992), que obtiveram o estabelecimento de ápices meristemáticos da cultivar 'Gala' em meio de cultura na presença dos mesmos fitorreguladores e nas mesmas concentrações. $\mathrm{O}$ conjunto destes resultados reforça a premissa de GEORGE (1996), segundo o qual, as citocininas, as auxinas e o ácido giberélico, adicionados conjuntamente ao meio de cultura, são necessários para promover o crescimento e o desenvolvimento de ápices meristemáticos in vitro.

\section{Indução de brotações}

$\mathrm{O}$ meio de cultura MS, contendo $2,2 \mu \mathrm{M}$ de BAP, promoveu a produção de 2,6 brotações por meristema inoculado, os quais apresentaram uma altura média de $13 \mathrm{~mm}$. Este tratamento foi superior ao tratamento com $4,4 \mu \mathrm{M}$ de BAP (Tabela 1). Os resultados obtidos neste trabalho são semelhantes aos obtidos por YUI et al. (1993). Com o portaenxerto 'M-7', os autores obtiveram o maior número de brotações com altura superior a $10 \mathrm{~mm}$ quando utilizaram $2,2 \mu \mathrm{M}$ BAP no meio de cultura. Possivelmente, a maior concentração de BAP utilizada para o porta-enxerto 'Seleção 69' inibiu a formação de novos meristemas. SKOOG et al. (1965) dão suporte a esta hipótese, pois observaram que a divisão celular é dependente da concentração de citocinina no meio, do genótipo e das condições de cultura. Para o porta-enxerto 'Seleção 69', as altas con-

Tabela 1 - Efeito de diferentes concentrações de BAP (6Benzilaminopurina) sobre o número e o comprimento das brotações do porta-enxerto de macieira 'Seleção 69', após 40 dias de cultivo in vitro, em meio de cultura MS. CCA/UFSC, 1998/99.

\begin{tabular}{lcc}
\hline $\begin{array}{c}\text { Concentrações } \\
\text { de BAP }\end{array}$ & $\begin{array}{c}\text { Número de } \\
\text { brotações }\end{array}$ & $\begin{array}{c}\text { Altura das } \\
\text { brotações (mm) }\end{array}$ \\
\hline $2,2 \mu \mathrm{M}$ & $2,6 \mathrm{a} *$ & $13 \mathrm{a}$ \\
$4,4 \mu \mathrm{M}$ & $1,9 \mathrm{~b}$ & $10 \mathrm{~b}$ \\
Média & 2,3 & 11,5 \\
C.V. $(\%)$ & 24,9 & 26,4 \\
\hline
\end{tabular}

*Médias seguidas pela mesma letra em cada coluna não diferem significativamente, pelo teste de Duncan, a 5\% de probabilidade de erro.

Ciência Rural, v. 31, n. 5, 2001. 
centrações de BAP podem ter diminuído as taxas de divisão celular e provocado um menor efeito sobre o número e a altura das brotações produzidas.

\section{Multiplicação das brotações em diferentes com- posições salinas \\ O meio de cultura MS promoveu a indu-} ção de 2,5 brotações por explante inoculado, não diferindo do meio de cultura Cheng, que induziu 2,0 brotações por explante. No entanto, o meio de cultura MS foi superior ao meio QL, que induziu 1,4 brotações por explante (Tabela 2). O número de brotações obtido no meio de cultura QL, para o porta-enxerto 'Seleção 69', foi menor que o obtido por FERRADINI et al. (1996) para o porta-enxerto de macieira 'M-26'. A diferença entre estes resultados pode ser atribuída ao efeito do genótipo.

Além disso, no meio de cultura QL, as folhas das plantas do porta-enxerto 'Seleção 69' apresentaram coloração verde clara, ao passo que nos meios de cultura MS e Cheng, contendo maiores concentrações de alguns nutrientes, as folhas apresentaram coloração verde intensa. A principal variação entre os meios de cultura é a fonte de nitrogênio. Este resultado pode estar relacionado com a pequena quantidade de nitrogênio na forma de íon amônio no meio de cultura QL. O meio de cultura QL apresenta $4,2 \%$ do nitrogênio na forma do íon amônio $\left(\mathrm{NH}_{4}^{+}\right)$ e $95,8 \%$ na forma do íon nitrato $\left(\mathrm{NO}_{3}{ }^{-}\right)$, enquanto que os meios de cultura MS e Cheng apresentam $34,4 \%$ do nitrogênio na forma do íon amônio e $65,6 \%$ na forma do íon nitrato. Comparado com o íon nitrato, o qual é a forma de nitrogênio altamente oxidada, o íon amônio é a forma de nitrogênio altamente reduzida sendo esta, a forma de nitrogênio

Tabela 2 - Efeito de diferentes concentrações salinas dos meios de cultura sobre o número e a altura das brotações do porta-enxerto de macieira 'Seleção 69', após 50 dias de cultivo in vitro. CCA/UFSC, 1998/99.

\begin{tabular}{lcc}
\hline \multicolumn{1}{c}{ Meios de cultivo } & $\begin{array}{c}\text { Número de } \\
\text { brotações }\end{array}$ & $\begin{array}{c}\text { Altura das } \\
\text { brotações }(\mathrm{cm})\end{array}$ \\
\hline MS & $2,5 \mathrm{a} *$ & $2,0 \mathrm{a}$ \\
Cheng & $2,0 \mathrm{ab}$ & $1,7 \mathrm{a}$ \\
Quoirin \& Lepoivre (QL) & $1,4 \mathrm{~b}$ & $1,2 \mathrm{a}$ \\
Média & 1,9 & 1,6 \\
C.V. $(\%)$ & 30,8 & 43,6 \\
\hline
\end{tabular}

*Médias seguidas pela mesma letra em cada coluna não diferem significativamente, pelo teste de Duncan, a $5 \%$ de probabilidade de erro. que as plantas utilizam preferencialmente no metabolismo celular (GEORGE, 1996).

\section{Alongamento das brotações}

Não foram observados aumentos na altura das brotações em função da presença de $\mathrm{GA}_{3}$ no meio de cultura (Tabela 3). Estes resultados estão de acordo com os obtidos por RIBAS \& ZANETTE (1992), os quais observaram que, apesar do efeito deste promotor de crescimento sobre a elongação das plantas, o $\mathrm{GA}_{3}$ adicionado ao meio de cultura não proporcionou aumento na altura das brotações das cultivares 'Golden Delicious' e 'Gala'. Para o porta-enxerto 'Seleção 69', em alguns tratamentos, a presença de $\mathrm{GA}_{3}$ teve efeito inibitório no alongamento das brotações. Possivelmente, a autoclavagem do meio de cultura pode ter reduzido o efeito do $\mathrm{GA}_{3}$. Esta hipótese está baseada nas constatações de YUI et al. (1993) e PEDROTTI et al. (1994). Para estes autores, algumas substâncias orgânicas são parcialmente degradadas pela autoclavagem, o que reduz a sua atividade biológica. Nesta condição, o $\mathrm{GA}_{3}$, deve ser filtroesterilizado e adicionado ao meio de cultura após sua autoclavagem.

Para o porta-enxerto 'Seleção 69', a adição de $1,0 \mu \mathrm{M}$ de AIB, combinado com $2,2 \mu \mathrm{M}$ de BAP proporcionou aumento na altura das brotações, quando comparado com o meio de cultura contendo $2,2 \mu \mathrm{M}$ de BAP combinado com 0,5, 1,0 e 1,5 $\mu \mathrm{M}$ de $\mathrm{GA}_{3}$ (Tabela 3). Estes resultados estão de acordo com os obtidos por DUSTAN et al. (1985), que aumentaram a altura das brotações do porta-enxerto 'M-4' com a adição de $1,0 \mu \mathrm{M}$ de AIB no meio de cultura e corroboram a premissa de GEORGE (1996) segundo o qual, as auxinas estão envolvidas na promoção do alongamento celular em algumas espécies. Em função destes resultados, o meio de cultura MS, contendo $2,2 \mu \mathrm{M}$ de BAP e $1,0 \mu \mathrm{M}$ de AIB, foi adotado para as fases de multiplicação e alongamento das brotações deste porta-enxerto.

\section{Enraizamento ex vitro e aclimatização}

Não foram observadas diferenças estatísticas no enraizamento ex vitro das microestacas em função das concentrações de AIB utilizadas (Tabela 4). A taxa de sobrevivência das plantas do portaenxerto 'Seleção 69', após 30 dias de cultivo na sala de aclimatização foi em média 77,3\%. Este resultado indica que, em virtude das condições fornecidas pelo conjunto de fatores envolvidos no enraizamento $\boldsymbol{e x}$ vitro deste porta-enxerto, não é necessária a aplicação de AIB para a indução de raízes, reduzindo os custos de mão-de-obra para o preparo das microestacas. Além disso, o sistema de enraizamento ex vitro 
Tabela 3 - Efeito de fitorreguladores de crescimento (BAP, AIB e GA 3 ) sobre a altura, número brotações e o número gemas por brotação do portaenxerto de macieira 'Seleção 69', após 50 dias de cultivo in vitro. CCA/UFSC, 1998/99.

\begin{tabular}{|c|c|c|c|}
\hline $\begin{array}{l}\text { Fitorreguladores de crescimento } \\
\qquad(\mu \mathrm{M})\end{array}$ & $\begin{array}{c}\text { Altura das } \\
\text { brotações } \\
(\mathrm{mm})\end{array}$ & $\begin{array}{l}\text { Número } \\
\text { de } \\
\text { brotações }\end{array}$ & $\begin{array}{c}\text { Número de } \\
\text { gemas/ } \\
\text { brotação }\end{array}$ \\
\hline T1 - BAP 2,22 & $18 \mathrm{ab} *$ & 1,9 bc & $6,2 \mathrm{~b}$ \\
\hline $\mathrm{T} 2-\mathrm{BAP} 2,22+\mathrm{GA}_{3} 0,5$ & $14 \mathrm{c}$ & $1,4 \quad \mathrm{c}$ & $5,2 \mathrm{~b}$ \\
\hline $\mathrm{T} 3-\mathrm{BAP} 2,22+\mathrm{GA}_{3} 1,0$ & $17 \mathrm{bc}$ & $2,2 \mathrm{ab}$ & $9,5 \mathrm{a}$ \\
\hline $\mathrm{T} 4-\mathrm{BAP} 2,22+\mathrm{GA}_{3} 1,5$ & $15 \mathrm{bc}$ & $2,6 \mathrm{a}$ & $10,7 \mathrm{a}$ \\
\hline T5 - BAP $2,22+$ AIB 0,5 & $19 \mathrm{ab}$ & $2,0 \mathrm{bc}$ & $9,4 \mathrm{a}$ \\
\hline T6 - BAP $2,22+$ AIB 1,0 & $23 \mathrm{a}$ & $1,8 \mathrm{bc}$ & $9,9 \mathrm{a}$ \\
\hline T7 - BAP $2,22+$ AIB $1,0+\mathrm{GA}_{3} 1,5$ & $21 \mathrm{a}$ & $2,0 \quad b$ & $11,2 \mathrm{a}$ \\
\hline Média & 18,1 & 1,9 & 8,9 \\
\hline C.V. $(\%)$ & 18,8 & 21,9 & 32,8 \\
\hline
\end{tabular}

*Médias seguidas pela mesma letra em cada coluna não diferem significativamente, pelo teste de Duncan, a $5 \%$ de probabilidade de erro.

permitiu que as raízes de Acer rubrum, Betula nigra e Malus x domestica, induzidas nesta condição, apresentaram maior sobrevivência do que aquelas induzidas nos sistemas tradicionais in vitro (McCLELLAND et al., 1990). Este é um fator importante, visto que o sistema radicular pode rapidamente fornecer água e nutrientes, que são essenciais à retomada de crescimento das plantas após sua transferência para a casa de vegetação. Os dados obtidos neste trabalho abrem boas perspectivas para o uso da técnica de indução do enraizamento ex vitro

Tabela 4 - Efeito das concentrações de $\operatorname{AIB}\left(0,1\right.$ e $\left.2 \mathrm{~g} \mathrm{~L}^{-1}\right)$ sobre a percentagem de enraizamento, número de folhas, altura das plantas, número e comprimento das raízes do porta-enxerto de macieira 'Seleção 69', 30 dias após a indução ao enraizamento realizado $\boldsymbol{e} \boldsymbol{x}$ vitro e a aclimatização em substrato contendo solo argiloso e casca de arroz carbonizada na proporção de 1:1 (v.v). CCA/UFSC, 1998/99.

\begin{tabular}{cccccc}
\hline $\begin{array}{c}\text { AIB } \\
\left(\mathrm{g} \mathrm{L}^{-1}\right)\end{array}$ & $\begin{array}{c}\text { Percentagem } \\
\text { de enraiza- } \\
\text { mento }\end{array}$ & $\begin{array}{c}\text { Número } \\
\text { de } \\
\text { folhas }\end{array}$ & $\begin{array}{c}\text { Altura da } \\
\text { parte aérea } \\
(\mathrm{mm})\end{array}$ & $\begin{array}{c}\text { Número } \\
\text { de } \\
\text { raízes }\end{array}$ & $\begin{array}{c}\text { Comprimento } \\
\text { das } \\
\text { raízes }(\mathrm{mm})\end{array}$ \\
\hline 0 & $84 \mathrm{a}^{*}$ & $5,8 \mathrm{a}$ & $23 \mathrm{a}$ & $5,1 \mathrm{a}$ & $27 \mathrm{a}$ \\
1 & $72 \mathrm{a}$ & $5,6 \mathrm{a}$ & $23 \mathrm{a}$ & $5,4 \mathrm{a}$ & $27 \mathrm{a}$ \\
2 & $76 \mathrm{a}$ & $6,1 \mathrm{a}$ & $21 \mathrm{a}$ & $5,9 \mathrm{a}$ & $21 \mathrm{a}$ \\
Média & 77,3 & 5,8 & 22,3 & 5,5 & 25 \\
C.V. $(\%)$ & 10,8 & 29,3 & 25,6 & 62,3 & 48,9 \\
\hline
\end{tabular}

*Médias seguidas pela mesma letra em cada coluna não diferem significativamente, pelo teste de Duncan, a 5\% de probabilidade de erro. em programas de micropropagação massal deste porta-enxerto, em acordo com aqueles obtidos por PEDROTTI \& VOLTOLINI (1997), com o porta-enxerto 'M-9'.

\section{CONCLUSÕES}

a) o protocolo testado proporciona resultados adequados à produção massal de mudas de macieira do porta-enxerto 'Seleção 69' isentas de viroses; b) para a multiplicação, os melhores resultados foram obtidos com a utilização do meio de cultura MS suplementado com de $2,2 \mu \mathrm{M}$ de BAP; c) $\mathrm{O}$ alongamento das brotações foi promovido com a adição de 1,0 $\mu \mathrm{M}$ de AIB ao meio de cultura MS; d) Para o enraizamento de microestacas ex vitro e aclimatização, as concentrações de AIB utilizadas não diferiram entre si quanto à percentagem de enraizamento, número e comprimento das raízes, número de folhas e altura da parte aérea das plantas.

\section{REFERÊNCIAS BIBLIOGRÁFICAS}

ASSOCIAÇÃO BRASILEIRA DOS PRODUTORES DE MAÇÃ. Encontro Nacional Sobre Fruticultura Temperada, 2. Fraiburgo-SC : EPAGRI/ABPM, 1999. 157p.

CENTELLAS, A.Q., FORTES, G.R.D., MULLER, N.T.G., et al. Effects of synthetic auxins on the in vitro rooting of apple tree. Pesquisa Agropecuária Brasileira, Brasília, v.34, n.2, p.181-186, 1999.

CHENG, T.Y. Clonal propagation of woody species through tissue techniques. Combined Proceedings International Plant Propagation Society, Alexandria, n.28, p.139-155, 1978.

DENARDI, F., BERTON, O. Resistência de portaenxertos de macieira ao fungo Rosellinia necatrix Prill. no Meio Oeste Catarinense. Agropecuária Catarinense, Florianópolis, v.8, n.4, p.25-27, 1995.

DIAZ-PÉREZ, J.C., SUTTER; E.G., SHACKEL, K.A. Acclimatization and subsequent gasexchange, water relations, survival and growth of microcultured apple plantlets after transplanting them in soil. Physiologia Plantarum, Copenhagen, n.95, p.225-232, 1995.

DUSTAN, D.I., TURNER, K.E., LAZAROFF, W.R. Propagation in vitro of apple rootstock 'M-4': effect of phytohormones on shoot quality. Plant Cell, Tissue and Organ Culture, Dordrecht, v.4, p.55-60, 1985.

FERRADINI, N., FAMIANI, F., PROIETTI, P., et al. Influence of growth regulators and light on 
in vitro shoot regeneration in ' $\mathrm{M}-26$ ' apple rootstock. Journal of Horticultural Science, Alexandria, v.6, n.71, p.859-6865, 1996.

GEORGE, E.F. Plant propagation by tissue culture. Part 2. Pratice. 2ed. Edington: Exegetics, 1996. 1361p.

McCLELLAND M.T., SMITH M.A.L., CAROTHERS, Z.B. The effect of in vitro and ex vitro root initiation on subsequent microcutting root quality in three woody plants. Plant Cell, Tissue and Organ Culture, Dordrecht, v.21, n.2, p.115-123, 1990.

MURASHIGE, T., SKOOG, F. A revised medium for rapid growth and biossay with tobacco tissue cultures. Physiologia Plantarum, Copenhagen, n.15, p.473-497, 1962.

NUNES, J.C.O., BARP, A., SILVA, F.C., et al. Micropropagação do porta-enxerto 'Marubakaido' (Malus prunifolia) a partir da cultura de meristemas. Revista Brasileira de Fruticultura, Jaboticabal, v.21, n.2, p.191-195, 1999.

PEDROTTI, E.L. Etude de l'oraganogenèse in vitro a partir de racines, de feuilles et d'embryons zygotiques de merisier (Prunus avium L.). Orleans, 1993. 101p. Tese (Doutorado em Biologia e Fisiologia Vegetal) - Universitè D’Orleans, 1993.

PEDROTTI, E.L., JAY-ALLEMAND, C., DOUMAS, P., et al. Effect of autoclaving amino acids on in vitro rooting response of wild cherry shoot. Scientia Horticulturae, Amsterdan, v.57, p.89-96. 1994

PEDROTTI, E.L., VOLTOLINI, J.A. Enraizamento ex vitro e aclimatização dos porta-enxertos de macieira 'Marubakaido' e 'M-9'. In: ENCONTRO BRASILEIRO DE BIOTECNOLOGIA VEGETAL, 2. Gramado, RS. Anais... Gramado-RS : REDBIO, 1997. v.1, p.67.

QUOIRIN, M., LEPOIVRE, P. Improved media for in vitro culture of Prunus sp. Acta Horticulturae, Wageningen, v.78, p.437-442, 1977.

RIBAS, L.L.F., ZANETTE, F. Propagação da macieira c.v. 'Gala' através da cultura de meristemas. Revista Brasileira de Fisiologia Vegetal, Lavras, v.1, n.4, p.39-43, 1992.

SKOOG, F., STRONG, F.M., MILlER, C.O. Cytokinins. Science, Washington, v.148, p.532-533, 1965.

ZIMMERMAN, R.H. Apple. In: SHARP, W.R., EVANS, D.A., AMMIRATO, P. V., et al. (Eds). Handbook of plant cell culture. New York: Macmillan, 1984. v.2, p.369-395.

YUI, E., PASQUAL, M., RAMOS. J.D., et al. Influência de reguladores de crescimento na proliferação in vitro de brotos de porta-enxerto de macieira 'M-7'. Pesquisa Agropecuária Brasileira, Brasília, v.28, n.5, p.597-602, 1993.

Ciência Rural, v. 31, n. 5, 2001. 